\title{
Libertad, igualdad, sostenibilidad. Por un ecofeminismo ilustrado
}

\section{Liberty, Equality, Sustainability. For an Enlightened Ecofeminism}

\author{
Alicia H. PuleO
}

Universidad de Valladolid

\begin{abstract}
RESUMEN. En este artículo se presenta la propuesta de un ecofeminismo ilustrado entendido como reflexión ético-política sobre las relaciones de los humanos con la Naturaleza. Orientado a la ecojusticia y la sostenibilidad, el ecofeminismo ilustrado se caracterizaría por la crítica al prejuicio, la defensa de los principios de igualdad y autonomía, la conceptualización nominalista del género, el diálogo intercultural, la aceptación prudente de la ciencia y la técnica, la universalización de las virtudes del cuidado aplicadas a los humanos y al resto de la Naturaleza, y una moral de la compasión frente a la radical finitud del mundo.
\end{abstract}

Palabras clave: libertad, igualdad, sostenibilidad, ecofeminismo.
ABSTRACT. This article presents the proposal of an enlightened Ecofeminism and defines it as an ethic-political thinking about human relations to Nature. It aims at ecojustice and sustainability, which are characterized through the criticism of prejudice, through the principles of equality and autonomy, and through the nominalist conceptualization of gender, intercultural dialogue and the sensible acceptance of science and technique. The enlightened Ecofeminism universalizes virtues such as caring for the human and non-human $\mathrm{Na}$ ture, and defends a compassionate moral towards the radical finitude of the world.

Key words: liberty, equality, sustainability, ecofeminism.

Con la acerada precisión de su pensamiento intempestivo, Celia Amorós ha señalado que, así como hemos hecho pasar un test de feminismo a la Ilustración ${ }^{1}$, habíamos de llevar adelante la operación complementaria de someter

1 De las numerosas publicaciones dedicadas a esta tarea y realizadas por el grupo investigador reunido desde finales de los años ochenta en torno al Seminario Permanente Feminismo e Ilustración que fuera creado por Celia Amorós en la Universidad Complutense de Madrid, pueden consultarse, entre otras, las siguientes obras: Celia Amorós y Ana de Miguel (eds.), Historia de la teoría feminista. De la Ilustración a la globalización, 3 volúmenes, ed. Minerva, Madrid, 2005; C. Amorós (dir.), Actas del Seminario Feminismo e Ilustración, Instituto de Investigaciones Feministas, Universidad Complutense de Madrid, 1992; C. Amorós (dir.), 10 palabras clave sobre Mujer, Ed. Verbo Divino, Estela, 1995; Neus Campillo, Crítica, libertad y feminismo. La conceptualización del sujeto, Episteme, Valencia, 1995; Rosa Cobo, Funda- 
los desarrollos teóricos feministas a un examen de valores ilustrados a efectos de estimar su potencial emancipatorio ${ }^{2}$.

Probablemente, la mayoría de las teorías ecofeministas existentes no resistiría semejante prueba. En sus pensadoras más destacadas, he encontrado reflexiones originales y muy sugerentes sobre la civilización tecnológica que nos ha tocado vivir. Pero casi todas estas autoras parecen sentirse obligadas a renegar de la Ilustración y de sus valores. Algunas han desarrollado un esencialismo diferencialista de dudosos resultados emancipatorios que las mismas pensadoras ecofeministas de última generación, desde posiciones deconstructivas, han calificado de «feminismo de la inversión acrítica» ${ }^{3}$. En lo que concierne a la ética, a menudo rechazan el lenguaje de los derechos por considerarlo masculinista y pretenden reeemplazarlo por la ética del cuidado o por consideraciones contextuales fuertemente marcadas por el comunitarismo y el multiculturalismo.

¿Es posible un ecofeminismo que reivindique el legado ilustrado de igualdad y autonomía y que conserve el sentido fuerte de «eco», es decir, que no se limite a un simple ambientalismo feminista en el que las relaciones con la Naturaleza son sólo buena gestión de los «recursos»? ¿Cuáles serían sus rasgos fundamentales? En los tiempos del cambio climático, creo que vale la pena intentar responder a estos interrogantes.

El proceso de desarrollo de la Modernidad arroja luces y sombras con respecto a las mujeres. Si bien se ha señalado el establecimiento de un «contrato sexual» ${ }^{4}$ que funciona como subtexto de género del discurso del contrato social, también se ha destacado que la fuerza del pensamiento crítico y la idea de la igualdad de todos los hombres han sido decisivos para la emergencia de

mentos del patriarcado moderno. Jean-Jacques Rousseau, Cátedra, Madrid, 1995; Ana de Miguel, Cómo leer a John Stuart Mill, ed. Júcar, Gijón-Madrid, 1994; Cristina Molina Petit, Dialéctica feminista de la Ilustración. Anthropos, Barcelona, 1994; Luisa Posada Kubissa, «Cuando la razón práctica no es tan pura. (Aportaciones de la hermenéutica feminista alemana actual: a propósito de Kant)», en C. Amorós (ed.): «Feminismo y ética», en Isegoría. Revista de Filosofía Moral y Politica n. ${ }^{\circ}$ 6, CSIC, Instituto de Filosofía. Madrid (noviembre 1992), pp. 17-36; Alicia H. Puleo (ed.), Condorcet, De Gouges, De Lambert. La Ilustración olvidada. La polémica de los sexos en el siglo XVIII, Presentación de Celia Amorós, Anthropos, Barcelona, 1993; Concha Roldán, «El reino de los fines y su gineceo: las limitaciones del universalismo kantiano a la luz de sus concepciones antropológicas», en Roberto Aramayo, Javier Muguerza y Antonio Valdecantos (comp.), El individuo y la historia. Antinomias de la herencia moderna, ed. Paidós, Barcelona, 1995.

2 C. Amorós, Tiempo de feminismo. Sobre feminismo, proyecto ilustrado y postmodernidad, Cátedra, Madrid, 1997, cap. II.

${ }^{3}$ La expression pertenece a Val Plumwood (cf. Feminism and the Mastery of Nature, Routledge, London \& New York, 1993, pp. 31 y ss.).

${ }^{4}$ El contrato sería, según Pateman, el medio a través del cual se instituyen, al tiempo que se ocultan, las relaciones de subordinación de las mujeres en la Modernidad (cf. Carole Pateman, El contrato sexual, introducción de María-Xosé Agra, trad. M. ${ }^{a}$ Luisa Femenías, revisión de M. X. Agra, Anthropos, Barcelona, 1995). 
las reivindicaciones de las mujeres. Podemos hablar, pues, de más de dos siglos de teoría y praxis feministas. Se trata de una tarea colectiva ${ }^{5}$, aún inacabada, para acceder al rango de individuo y a una plena ciudadanía ${ }^{6}$. En las cuatro últimas décadas, el neofeminismo ha manifestado una extraordinaria multiplicidad de intereses y marcos teóricos y ha sabido responder a los retos de distintos debates emergentes con propuestas innovadoras y fecundos análisis que no habrían podido ser elaborados desde una perspectiva ciega al enfoque crítico de género. Los enfoques de clase, raza y diversidad sexual, las teorías sobre el sujeto, la ética y la filosofía política se han visto notablemente enriquecidos por un pensamiento que da la voz a las mujeres en un impulso emancipatorio inédito. En cuanto a la relación con la Naturaleza, podríamos decir que la racionalidad moderna nos ha aportado, en su conjunto, grandes cotas de bienestar pero también amenazas y problemas globales nuevos. En los últimos años, a pesar de los interesados silencios en torno a los problemas ambientales, sectores cada vez más amplios de la población mundial han adquirido conciencia de la crisis ecológica. Ante una degradación de los ecosistemas que hace todavía más dura la vida cotidiana de los más pobres en los países «en desarrollo», se ha comenzado a vincular los derechos humanos y la protección ambiental; el ideal de justicia se ha ampliado a la ecojusticia. Lo que era hasta ayer la convicción de unos pocos científicos y militantes proteccionistas y ecologistas se convierte gradualmente en la certeza de una asignatura pendiente ante un problema que afecta a nuestra salud, destruye la biodiversidad y compromete seriamente el porvenir humano en la Tierra ${ }^{7}$. Esta nueva amenaza se hace patente en un ya largo período de desconcierto y apatía ciudadana ${ }^{8}$. Por otro lado, y más allá del riesgo, la ecoética implica

5 Amelia Valcárcel, Sexo y Filosofía. Sobre «Mujer»y «Poder», Anthropos, Barcelona, 1991.

6 Para las dimensiones de esta ciudadanía, ver Alicia Miyares, Democracia feminista, Cátedra, Madrid, 2003.

7 El documental del demócrata norteamericano Al Gore, Una verdad incómoda (An Inconvenient Truth, 2006), marca probablemente un hito en el reconocimiento internacional de la crisis ecológica y en el afianzamiento y popularización de la propuesta de un capitalismo verde. Desde esta perspectiva, el cuidado del medio ambiente es presentado como promesa y proyecto de mayores ganancias económicas, como fuente de enriquecimiento más moderna y menos destructiva. Sobre las dificultades del pensamiento liberal para convertirse en ecológico, ver Joaquín Valdivielso Navarro, «El problema de la extensión de la comunidad de justicia en el liberalismo "verde" rawlsiano», en Jorge Riechmann (coord.), Ética ecológica. Propuestas para una reorientación, ed. Nordan-Comunidad, Montevideo, Uruguay, 2004, pp. 109-128. Consultar también Andrew Dobson, «El liberalismo y la política de la ecología», Revista Internacional de Filosofía Política, n. ${ }^{\circ}$ 13, julio 1999, pp. 11-20.

8 Sobre la crisis de la izquierda y la necesidad de su reformulación ecológica, ver Francisco Fernández Buey, «Materiales para una ética de la resistencia» (en F. Fernández Buey y J. Riechmann, Ni tribunos. Ideas y materiales para un programa ecosocialista, Siglo XXI, Madrid, 1996, pp. 3-203). 
también un acercamiento nuevo a la antigua cuestión de la búsqueda de la felicidad ${ }^{9}$.

Hace ya casi tres décadas que el feminismo ha aceptado el desafío de reflexionar sobre la crisis ecológica desde sus claves propias. El resultado ha sido la aparición en escena del ecofeminismo ${ }^{10}$ : un intento de abordar la cuestión medioambiental desde las categorías de mujeres, género, androcentrismo, patriarcado, sexismo, cuidado, etc. Tal enfoque facilitaría la comprensión de los problemas específicos de las mujeres en relación con el medio ambiente y enriquecería la misma teoría ecológica con la lectura feminista de la realidad, corrigiendo sus sesgos androcéntricos y contribuyendo a encontrar soluciones para alcanzar la sostenibilidad. Como ha apuntado María Xosé Agra, «el ecofeminismo aporta elementos interesantes en tanto que perspectiva crítica respecto al concepto de naturaleza y de los dualismos» ${ }^{11}$

En artículos anteriores ${ }^{12}$, he expuesto los distintos tipos de ecofeminismo existentes, intentando llevar a cabo una clasificación que, a riesgo de esquematizar, pudiera servir de mapa del nuevo territorio. En este trabajo, en cambio, querría esbozar las principales líneas de un ecofeminismo que no caiga en la habitual renuncia al universalismo ilustrado y a sus ideales reguladores.

Mi propuesta se basa en la afirmación de que un ecofeminismo que evite los peligros que esta renuncia encierra para las mujeres debería tener las siguientes características fundamentales: 1) Ser un pensamiento crítico; 2) Reivindicar la igualdad y la autonomía de las mujeres; 3) Aceptar con prudencia los beneficios de la ciencia y la técnica; 4) Fomentar la universalización de los valores de la ética del cuidado hacia los humanos y la Naturaleza; 5) Asumir el diálogo intercultural; 6) afirmar la unidad y continuidad de la Naturaleza desde el conocimiento evolucionista y el sentimiento de compasión.

9 Carmen Velayos propone que la ecoética conceda más importancia a las emociones positivas y a las prácticas tendentes a la felicidad. Apelar sólo al temor tendría un efecto paralizante y no profundizaría en todas las posibilidades de la superación del antropocentrismo fuerte. Cf. Carmen Velayos, «Deberes y felicidad en la ecoética», Isegoría. Revista de Filosofía Moral y Política, n. ${ }^{\circ}$ 32, CSIC, Instituto de Filosofía. Madrid (junio 2005), pp. 145-156. En otro registro, también cultiva esta idea Joaquín Araujo en Ecos... lógicos. Para entender la Ecología, (MAEVA, Madrid, 2000).

10 Utilizaré el término ecofeminismo para referirme tanto a las teorías llamadas «clásicas» como a las más recientes, deconstructivas, que se autodesignan como feminismo ecológico para diferenciarse de las primeras.

11 María Xosé Agra, «Introducción», en M. X. Agra, Ecología y Feminismo, ed. Ecorama, Granada, 1997, p. 20.

12 Ver A. Puleo, «Del ecofeminismo clásico al deconstructivo: principales corrientes de un pensamiento poco conocido», en Celia Amorós y Ana de Miguel (eds.), Teoría feminista. De la Ilustración a la globalización, ed. Minerva, Madrid, 2005, pp. 121-152; A. Puleo, «Género, naturaleza y ética», editado en José María García Gómez-Heras y Carmen Velayos Castelo, Tomarse en serio la naturaleza: ética ambiental desde una perspectiva multidisciplinar, ed. Biblioteca Nueva, Madrid, 2004, pp. 97-114; A. Puleo, «Luces y sombras de la teoría y la praxis ecofeminista», en María Luisa Cavana, Alicia Puleo y Cristina Segura, Mujeres y Ecología. Historia, Pensamiento, Sociedad, ed. Almudayna, Madrid, 2004, pp. 21-34. 
A la tematización, desde estas claves, del mundo humano y no humano en el marco de los crecientes problemas medioambientales le daré el nombre de ecofeminismo ilustrado.

\section{Ser un pensamiento crítico}

En una época marcada por cierta desafección con respecto al ejercicio reflexivo y por el avance de integrismos religiosos de diverso signo, se hace más necesario que nunca inscribir nuestra teoría ecofeminista en la tradición ilustrada de irracionalización de las doctrinas y prácticas opresivas.

Con la Ilustración se abandona la noción cartesiana de razón como conjunto de ideas innatas para abrazar la concepción de la razón como fuerza crítica que puede y debe aplicarse a todos los ámbitos ${ }^{13}$. Creencias y costumbres habrán de presentarse ante el tribunal de la razón. El pensador (que, en ocasiones, será pensadora), convertido en philosophe combativo, ya no escucha el consejo cartesiano de limitar las audacias críticas al ámbito epistemológico para evitar conflictos con los poderes establecidos. El espíritu de la Ilustración es analítico; reacio, por tanto, a toda palabra revelada y a toda mística ${ }^{14}$. El frontispicio de la Encyclopédie ${ }^{15}$ lo ilustra en una alegoría: mientras la Imaginación se apresta a adornar la Verdad con coronas de flores, la Razón trata de apartar sus velos. Aunque nos recuerde las patriarcales e infortunadas metáforas de Francis Bacon sobre el método científico ${ }^{16}$, esta imagen no deja de remitirnos a la voluntad ilustrada de conocer independientemente de los discursos mistificadores utilizados con harta frecuencia para objetivos de dominación.

Es preciso señalar, no obstante, que aun las corrientes de pensamiento más innovadoras y progresistas tienden a petrificarse y a convertirse, por ello mismo, en opresivas y limitadoras del propio pensar. Para que no sufra ese destino, la Ilustración ha de ser entendida como un proceso. Hay Ilustración mientras el pensamiento conserva su dinamismo sin convertirse en cuerpo doctrinal contrario a toda disidencia. Como señala Fernando Quesada, la tarea de nuestro presente post-metafísico consistiría en «asumir el sentido pro-

13 Ernst Cassirer, Filosofía de la Ilustración, trad. E. Imaz, F.C.E., México, 1943, p. 26; Georges Gusdorf, Les principes de la pensée au siècle des Lumières, vol. IV de Les sciences humanines et la pensée occidentale, Payot, Paris, 1971.

14 Armando Plebe, ¿Qué es verdaderamente la Ilustración?, ed. Doncel, Madrid, 1971.

15 Se trata de un grabado realizado a partir de un dibujo de Cochin y que se obsequiaba a todos los suscriptores de la obra.

16 Sobre las metáforas de Bacon, ver el ya clásico estudio de Carolyn Merchant, The Death of Nature: Woman, Ecology, and the Scientific Revolution (Harper and Row, San Francisco, 1981). 
fundo de la Ilustración en cuanto crítica y, consiguientemente, atreviéndonos a pensar por nosotros mismos, determinar sus límites (...) ${ }^{17}$.

La crítica no ha de estar dirigida únicamente a creencias, prejuicios y costumbres pre-modernas. Como ya plantearan los fundadores de la Escuela de Frankfurt, la razón misma tiende a convertirse en mito. Este fenómeno no sólo se expresa en esa reducción de la razón a mera razón instrumental enérgicamente denunciada por Horkheimer en su crítica al positivismo. También es visible actualmente en las resistencias numantinas a una revisión de las relaciones del «Hombre» con la «Naturaleza». La tendencia a evitar preguntas o críticas que nos exijan un replanteamiento de hábitos y creencias se traduce, así, en la automática acusación de irracionalismo, antihumanismo y romanticismo ${ }^{18}$ que recibe cualquier intento de dejar atrás el antropocentrismo extremo («fuerte» en la terminología al uso) y avanzar hacia un antropocentrismo moderado («débil») que tome en consideración a los pacientes morales no humanos y atienda a las condiciones de los sistemas que sustentan sus vidas y las nuestras. Desde tales posiciones, el debate es confinado en el círculo intrasocial, cuando la potencia destructiva de nuestra especie nos obliga a extender sin dilaciones el horizonte ético-político.

Puesto que el pensamiento ecologista se apoya en investigaciones científicas sobre el mundo natural y su capacidad de carga, propugna una sociedad basada en el principio de igualdad e invita a revisar críticamente las ideas preestablecidas sobre la vida buena, la justicia y el progreso moral y social, Andrew Dobson ha sostenido que, lejos de ser un romanticismo oscurantista, recoge y renueva la herencia ilustrada 19 .

En lo que concierne al feminismo, Celia Amorós ha señalado sus raíces racionalistas e ilustradas ${ }^{20} \mathrm{y}$, en la elocuencia de una acertada metáfora, Amelia Valcárcel lo ha caracterizado como «hijo no querido de la Ilustración» ${ }^{21}$. A pesar de ser el resultado lógico y esperable de la dinámica racionalista y democrática, el feminismo fue ridiculizado y estigmatizado durante mucho tiempo. Aún hoy continúa siendo atacado en nombre de los mismos

17 Fernando Quesada, Sendas de democracia. Entre la violencia y la globalización, ed. Homo Sapiens, Rosario, 2006, p. 55.

18 Un ejemplo de este tipo de acusaciones que hizo escuela es la obra de Luc Ferry, Le nouvel ordre écologique. L'arbre, l'animal et l'homme (Grasset, Paris, 1992). Sobre los límites de la racionalidad dialógico-discursiva habermasiana con respecto al problema ecológico, ver José María Gómez Heras, «Ética y medio ambiente. La descomposición y recomposición de la razón práctica», en Isegoría. Revista de Filosofía Moral y Política, n. ${ }^{\circ} 32$, CSIC, Instituto de Filosofía, Madrid (junio 2005), pp. 63-94.

19 Por otro lado, los verdes hablan «frecuentemente sotto voce en el idioma de la Ilustración», Andrew Dobson, Pensamiento político verde. Una nueva ideología para el siglo XXI, Paidós, Barcelona, 1997, p. 33.

20 Cf. Celia Amorós, Tiempo de feminismo. Sobre feminismo, proyecto ilustrado y postmodernidad, ed. cit.

21 Amelia Valcárcel, «Las filosofías políticas en presencia del feminismo», en Celia Amorós (ed.), Feminismo y Filosofía, Madrid, Síntesis, 2000, p. 116. 
principios de libertad e igualdad que lo alimentan. Se intenta, por ejemplo, dinamitar iniciativas para la igualdad como la discriminación inversa en nombre de la igualdad de todos los ciudadanos o se critica la penalización del acoso sexual que restringe la libertad de las mujeres clamando contra la represión del ciudadano por parte del Estado. Como ha apuntado Cristina Molina Petit, las Luces se resisten a iluminar el orden patriarcal ${ }^{22}$.

Tanto el feminismo como la ecología son productos de la Ilustración. Sin embargo, viendo en la «jaula de hierro» de la racionalidad moderna la causa de la destrucción medioambiental, la mayor parte de las teorías ecofeministas han exacerbado su crítica, proponiendo un reencantamiento del mundo natural destinado a devolverle a este último la dignidad que le había sido arrebatada. En ocasiones, este reencantamiento se plantea desde tradiciones con fuerte contenido patriarcal. Algunas teóricas, en el esfuerzo por desmarcarse de la demonización del varón propia del feminismo llamado «cultural» ${ }^{23}$ y para denunciar las nuevas formas de colonización que afectan a los países del Sur y crear amplios frentes de resistencia junto a los hombres, omiten toda crítica a las costumbres y prejuicios de las culturas pre-modernas. Sólo merece su condena el patriarcado capitalista occidental y tienden a idealizar la vida de las comunidades originarias ${ }^{24}$. Esta actitud quizás tenga eficacia estratégica alterglobalizadora y hasta puede ser el inicio del empoderamiento y de la conciencia feminista de muchas mujeres de países en vías de «mal desarrollo» 25 como lo demuestra la evolución del movimiento Chipko ${ }^{26}$ en la India. Pero suscita nuestro escepticismo. Un pensamiento se resiente con una aplicación tan desigual de la mirada crítica. En general, las mujeres poco podemos rescatar a nuestro favor del pasado y de las tradiciones referentes a los roles e identidades de género. El ecofeminismo ilustrado deberá convocar ante el tribunal de la razón a todas las costumbres basadas en pre-juicios patriarcales, aun aquellas que correspondan a culturas ecológicamente convenientes.

En otras corrientes y latitudes distintas, el reencantamiento se propone a través de la creación de nuevos mitos. En el ámbito de los cultos neopaganos que proliferan en el Primer Mundo y particularmente en América del Norte,

22 Cristina Molina Petit, op. cit.

23 Para una crítica a esta demonización ontologizante, ver Raquel Osborne, La construcción sexual de la realidad, Madrid, Cátedra, 1993.

24 Así, por ejemplo, en Vandana Shiva (Abrazar la vida. Mujer, ecología y desarrollo, trad. Instituto del Tercer Mundo de Montevideo [Uruguay], Cuadernos inacabados 18, ed. horas y HORAS, Madrid, 1995).

25 El concepto de mal desarrollo ha sido acuñado por Vandana Shiva para referirse a la exportación interesada hacia países del Sur de formas de producción destructivas de la biodiversidad, centradas en el mercado y generadoras de graves desequilibrios sociales.

26 Este movimiento de mujeres rurales del Himalaya surgió como una defensa de los bosques comunales en nombre del principio femenino de la Naturaleza y de la noción de satyagraha (fuerza de la verdad) y resistencia no violenta de Gandhi y desembocó más tarde en una lucha contra la violencia de género y a favor de la participación política de las mujeres. 
encontramos rituales de la Diosa que buscan revalorizar conjuntamente la Naturaleza y lo femenino: «Ella está dentro de todos nosotros. Ella es el círculo completo: tierra, aire, fuego, agua y esencia, cuerpo, mente, espíritu, emociones y cambio. (...) Todo procede de Ella; todo regresa a Ella. Como tierra, ella es también vida vegetal: árboles, hierbas y cereales que sostienen la vida. Ella es el cuerpo y el cuerpo es sagrado» ${ }^{27}$. Starhawk justifica esta nueva constelación mítica por la necesidad humana de símbolos trascendentes: si los antiguos sistemas de símbolos patriarcales no son reemplazados por otros de corte emancipatorio - sostiene - tienden a volver a instalarse con su carga opresiva ${ }^{28}$. Este argumento no carece de verosimilitud y contundencia cuando arrecian las exhortaciones a retornar a los dogmas patriarcales de las religiones del Libro para recuperar los valores en un mundo que ha perdido toda dimensión sagrada. Suponiendo que esta dimensión fuera indispensable para muchas personas, un panteísmo feminista que reconcilie a los humanos con la Tierra y el devenir me parece una expresión religiosa a la altura de los tiempos. También las ecofeministas católicas de la red latinoamericana Con-spirando apuestan por una creencia emparentada con el panteísmo y claramente feminista, dejando atrás la concepción de un Dios Padre trascendente y de un mundo espiritual escindido de la Naturaleza.

Estas prácticas religiosas dan seguridad, confianza y consuelo en una afirmación optimista de la unidad de la vida. Prescinden de un clero jerarquizado mediador, no tienen un cuerpo doctrinal fijo, predican la hermandad universal y buscan la reconciliación con el cuerpo y sus placeres. Tampoco se puede negar su carga crítica ${ }^{29}$. En algunos aspectos, podrían ser consideradas la expresión feminista y ecologista contemporánea del deísmo de las Luces.

Para quienes sientan necesidad de ritos y creencias en los que expresar su espiritualidad, es indudable que el culto neopagano de la Diosa y ciertas formas de la teología ecofeminista cristiana ofrecen opciones compatibles con un ethos emancipatorio ${ }^{30}$. Pero son cosmovisiones que precisan de la fe, la cual, como es sabido, es un don que no todo el mundo recibe. Probablemente, para muchas personas esta vía esté cerrada. Este problema no se le plantea a un ecofeminismo ilustrado. Basado en la idea de ecojusticia y en un materia-

27 Starhawk, La danza en espiral. El renacimiento de la antigua religión de la Gran Dio$s a$, Barcelona, ed. Obelisco, 2002, p. 139. Se trata de una actualización realizada por la autora de la edición original en inglés de 1979.

28 Ibid.

29 Carga crítica que les vale una inserción muy difícil y precaria en los márgenes de sus colectivos religiosos de pertenencia. Como señala la teóloga Mary Judith Ress (Ecofeminism in Latin America, Orbis Books, New York, 2006), incluso en las filas de la Teología de la Liberación, supuestamente más afín, las ecofeministas católicas apenas son escuchadas.

30 Sobre los rituales ecofeministas como forma de liderazgo compartido que trasciende la diferencia entre sacerdotes y laicas/os, empoderando a las mujeres, ver «Rituales: creaciones y poderes», monográfico de Con-spirando. Revista Latinoamericana de Ecofeminismo, Espiritualidad y Teología, n. ${ }^{\circ}$ 34, diciembre, 2000. 
lismo compasivo que pueda combatir el nihilismo consumista conducente a la paradoja del hedonismo, el ecofeminismo ilustrado puede contribuir a la construcción de una sociedad sostenible y justa sin el apoyo de los sentimientos místicos y religiosos.

\section{Reivindicar la igualdad y la autonomía de las mujeres}

Por lo general, la palabra «ecofeminismo» evoca desconfianza y rechazo entre las feministas porque se la asocia con teorías que identificaban a las mujeres con el mundo natural. Dado que el feminismo como teoría y como movimiento puede entenderse como un inmenso esfuerzo por liberar al colectivo femenino de las heterodesignaciones patriarcales ${ }^{31}$ y que la identificación de la Mujer con la Naturaleza ha sido un elemento importante del sistema de sexo-género ${ }^{32}$, puede entenderse perfectamente esta aprensión. Aunque no todas las pioneras del ecofeminismo pueden ser encerradas en una misma categoría ${ }^{33}$, las feministas de la diferencia han sido las más conocidas. El esencialismo de los textos «clásicos» ha sido presa fácil de la crítica no sólo por sus generalizaciones abusivas sobre las mujeres, sino por su peligro potencial de retorno a los estereotipos de la impotencia. La identificación de Mujer y Naturaleza, propia de numerosas culturas, forma parte de los discursos de legitimación patriarcal ${ }^{34}$. Los significados y el bajo estatus conferidos a ambas a lo largo de la constitución de la racionalidad occidental prueban abundantemente esta función legitimadora del dominio ${ }^{35}$. La participación en las guerras, el uso de las armas y el recurso habitual a la violencia han sido, y continúan siendo para amplios sectores de la humanidad, un elemento apreciado de la identidad masculina patriarcal. Para tomar un ejemplo ajeno a la mitolo-

31 Amelia Valcárcel, Sexo y Filosofía. Sobre «Mujer» y «Poder», ed. cit.

32 Sobre la identificación de la mujer con la sexualidad y la naturaleza, ver Alicia Puleo, Dialéctica de la sexualidad. Género y sexo en la filosofía contemporánea, Cátedra, Madrid, 1992. Para un estudio sobre la definición de los sentimientos morales en relación con la identidad femenina en la Ilustración francesa, ver Lieselotte Steinbrügge, The Moral Sex, Oxford University Press, 1995.

33 Ynestra King es una excepción importante en los escritos fundacionales.

34 Sobre la identificación de Mujer y Naturaleza, la antropóloga Sherry Ortner desarrolló las observaciones de Simone de Beauvoir en su famoso y discutido artículo «Is Female to Male as Nature is to Culture?» de 1972. En 1996, con «So, Is Female to Male as Nature Is to Culture?» revisa sus planteamientos y los matiza a la luz de la actual hegemonía post-estructuralista de su disciplina. Sin embargo, aunque recorta las aspiraciones de explicación universal de su primera hipótesis, se reafirma en sus líneas generales (Ambos artículos están recogidos en Sherry Ortner, Making Gender: The Politics and Erotics of Culture, Beacon Press, Boston, 1996, pp. 21-42 y pp. 173-180 respectivamente).

35 Ver Evelyn Fox Keller, Reflexiones sobre género y ciencia, Valencia, trad. Ana Sánchez, Alfons el Magnànim, 1991. 
gía guerrera occidental que nos es propia y que el cine americano de masas se ocupa diligentemente de renovar, recordaré que la antropología nos enseña que los varones de los pueblos melanésicos que practicaban la caza tribal de cabezas se autodesignaban con orgullo como dadores de Muerte frente a las mujeres a las que calificaban de dadoras de Vida ${ }^{36}$. La maternidad como destino, denunciada por Simone de Beauvoir, y la división sexual del trabajo pesan demasiado todavía sobre las vidas de muchas mujeres como para no temer el elogio a las capacidades de cuidado femeninas. La exaltación de la «gran diferencia» ${ }^{37}$ de los sexos de los ecofeminismos clásicos tiene escaso o nulo poder de transformación en el sistema estratificado de género.

Frente a posiciones diferencialistas que han ontologizado la bipolarización sexual patriarcal, el ecofeminismo ilustrado sólo reconocerá individuos. Esto no significa que pretenda ignorar los efectos que tiene sobre la individuación el locus en el sistema social de relaciones entre los sexos. En palabras de Celia Amorós, «ser nominalista moderada o no radical significa hacerse cargo de este tipo peculiar de entidad que los genéricos connotan negándose al mismo tiempo a esencializarla» ${ }^{38}$.

Roles, identidad sexuada, estereotipos, normas, sanciones y status son elementos constitutivos del sistema de género en el que todo self se incardina. Como sujetos, contribuimos a mantenerlo y, eventualmente, a transformarlo. El feminismo ha mostrado la posición subordinada del colectivo femenino y su deficitario acceso a los recursos y al reconocimiento en todas las sociedades conocidas. El ecofeminismo ha llamado la atención sobre los efectos negativos que el desarrollo destructor del medio natural ha tenido sobre numerosas mujeres rurales del Sur y ha dado a conocer internacionalmente su organización en movimientos de resistencia que, en ocasiones, han sido exitosos ${ }^{39}$. También ha señalado los distintos efectos nocivos de la sociedad química en consumidoras y productoras según su clase social y otros condicionantes tales como la raza.

Ante estos nuevos problemas, un ecofeminismo ilustrado debe reafirmar la tradicional sororidad internacional feminista, en este caso frente a la contaminación, la destrucción y la pobreza. Se trata, en otras palabras, de atender las demandas de ecojusticia del llamado ecologismo de los pobres, denunciando el mal desarrollo. No ha de pedir un nuevo sacrificio de las mujeres, esta vez para salvar el planeta y sus habitantes, plegándose a un nuevo movi-

36 Gilbert Herdt (ed.), Homosexualidad ritual en Melanesia, trad. José Lisón Arcal, Fundación Universidad-Empresa, UNED, Madrid, 1993.

37 En La gran diferencia y sus pequeñas consecuencias para las luchas de las mujeres (Cátedra, Madrid, 2005), obra que le ha valido el Premio Nacional de Ensayo, Celia Amorós desarrolla la tesis de que el énfasis en la diferencia sexual, vía elegida por algunas pensadoras como una posibilidad feminista, arroja deficientes resultados emancipatorios para las mujeres.

38 C. Amorós, La gran diferencia..., ed. cit., p. 113.

39 V. Shiva, op. cit. 
miento que coloque sus reivindicaciones en segundo lugar en lo que Celia Amorós ha llamado, justificadamente, «alianzas ruinosas» ${ }^{40}$ del feminismo. Tampoco ha de reducirse a mostrar a las mujeres como víctimas del deterioro ambiental. A pesar de sus limitaciones, la aplicación de la perspectiva de género en los proyectos de desarrollo ${ }^{41}$ favorece el empoderamiento de las mujeres y contribuye, por lo tanto, a la igualdad y la autonomía. Pero la creación de empleo para las mujeres, desde la doble perspectiva feminista y ecológica, exige proyectos de actividades sostenibles ${ }^{42}$.

La defensa de la igualdad y la autonomía de las mujeres no sólo concierne al acceso a los recursos ${ }^{43}$. Exige también el reconocimiento de las aportaciones de las mujeres, generalmente menospreciadas, como ha sido el caso del conocimiento del ecosistema en las mujeres rurales del Tercer Mundo, sistemáticamente ignorado por los expertos. Inspirada en esta reivindicación ecofeminista, la historiadora Cristina Segura ha planteado la conveniencia y oportunidad de iniciar una Historia ${ }^{44}$ de las actitudes medioambientales y de las prácticas productivas de las mujeres del pasado que utilizaría en sus investigaciones la metodología que ha permitido la realización de una Historia de las Mujeres frente a la ausencia de éstas en el canon. También se ha iniciado un rescate del olvido de las figuras de las precursoras en los ámbitos de la ciencia o la ética ecológica ${ }^{45}$.

40 Celia Amorós, Tiempo de feminismo. Sobre feminismo, proyecto ilustrado y postmodernidad, ed. cit., p. 321.

41 Sobre la forma de incorporar y evaluar la perspectiva de género en el desarrollo y en la cooperación para el desarrollo, ver Marta Carballo de la Riva (coord.), Género y desarrollo. El camino hacia la equidad, Instituto Universitario de Desarrollo y Cooperación, ed. Los Libros de la Catarata, 2006. Sobre las limitaciones del enfoque GED, ver María José Guerra y Aránzazu Hernández, «Mujeres, desarrollo y medio ambiente: Hacia una teoría ecofeminista de la justicia», en Isegoría. Revista de Filosofía Moral y Política, n. ${ }^{\circ} 32$, CSIC, Instituto de Filosofía, Madrid, junio 2005, pp. 185-200.

42 Ana Sabaté, introductora de la perspectiva ecofeminista en los estudios de Geografía realizados en nuestro país, muestra la agricultura ecológica en España como un sector fuertemente feminizado con problemas de abastecimiento en insumos y escasas redes de comercialización [ver Ana Sabaté y Magali Martínez, "Género y medio ambiente en el desarrollo rural», en Nieves López Estébanez, Emilia Martínez Garrido y Ester Sáez Pombo (eds.), Mujeres, medio ambiente y desarrollo rural, Ediciones de la Universidad Autónoma de Madrid, 2004, pp. 81-109].

43 Sobre el desarrollo de la autonomía y el liderazgo de las mujeres, ver Marcela Lagarde, Para mis socias de la vida, ed. horas y HORAS, Madrid, 2005.

44 Cristina Segura, «Historia ecofeminista», en María Luisa Cavana, Alicia Puleo y Cristina Segura, op. cit., pp. 35-50.

45 Rachel Carson, la bióloga que con su libro Silent Spring llevó el tema del riesgo de los pesticidas al debate público, es una de las más recordadas (María José Guerra, «¿Un vínculo privilegiado mujer-naturaleza? Rachel Carson y el tránsito de la sensibilidad naturalista a la conciencia ecológica», en María Luisa Cavana, Alicia Puleo y Cristina Segura, op. cit., pp. 119-127. Es menos conocida la escritora sueca Elin Wägner, temprana iniciadora del pensamiento ecofeminista (Katarina Leppänen, «En paz con la Tierra», en María Luisa Cavana, Alicia Puleo y Cristina Segura, op. cit., pp. 109-118. 
Reivindicar la igualdad y la autonomía implica, asimismo, promover los derechos sexuales y reproductivos. Frente a una difusa exaltación de la Vida y de la diversidad que esconde la tradicional negativa a dar autonomía sexual a las mujeres, un ecofeminismo ilustrado defenderá la libre determinación sobre el propio cuerpo. Es importante recordar que el texto en el que por primera vez se utilizó el término ecofeminismo era un artículo de Françoise d'Eaubonne que vinculaba la liberación del colectivo femenino con la necesaria disminución del crecimiento demográfico de acuerdo a criterios de libertad y sostenibilidad. La ecofeminista anarquista afirmaba: «En un mundo, o simplemente un país, donde las mujeres (y no, como puede ser el caso, una mujer) estuvieran realmente en el poder, su primer acto habría sido limitar y espaciar los nacimientos. Desde hace mucho tiempo, desde mucho antes de la superpoblación, es lo que siempre han intentado hacer» ${ }^{46}$.

De alguna manera, esta idea se ha debilitado en los desarrollos ecofeministas actuales. Así, Feminist International Network of Resistance to Reproductive and Genetic Engineering, organización presente en más de 35 países, denuncia las tecnologías reproductivas modernas como simple manipulación del cuerpo femenino que niega su fertilidad natural. Como observa Naila Kabeer ${ }^{47}$, la falta de matización en sus críticas resta credibilidad a sus posiciones. El total rechazo de la tecnología ignora las necesidades de numerosas mujeres pobres para quienes persiste el problema de la falta de capacidad de decisión sobre sus propios cuerpos. En ese sentido, algunos discursos ecofeministas en torno al crecimiento demográfico, como los de la alemana Maria Mies, destacada líder de la citada red, se acercan peligrosamente, bajo ropajes vanguardistas, a viejos mandatos opresivos ${ }^{48}$. Coincido con Joan Martínez Alier ${ }^{49}$ en considerar que el futuro del ecofeminismo pasa por un neomalthusianismo que haya incorporado las reivindicaciones de igualdad para las mujeres. Cuando la crítica al «patriarcado capitalista» cae en la mistificación de la natalidad en el Tercer Mundo, como fue el caso de Germaine Greer ${ }^{50}$, las mujeres concretas desaparecen como sujetos.

46 Françoise D’Eaubonne, «La época del ecofeminismo», en María Xosé Agra (comp.), Ecología y feminismo, ed. cit., p. 42.

47 Naila Kabeer, Realidades trastocadas. Las jerarquías de género en el pensamiento del desarrollo, trad. Isabel Vericat, Paidós-PUEG, México, 1998.

48 M. Mies y V. Shiva, La praxis del ecofeminismo. Biotecnología, consumo y reproducción, trad. Mireia Bofill y Daniel Aguilar, Icaria, Barcelona, 1998. De manera similar, la ecofeminista Susanne Kappeler califica a P. Singer y O. Kushe de especistas y legitimadores de siniestras operaciones eugenésicas. «Speciesism, Racism, Nationalism... or the Power of Scientific Subjectivity», in Carol Adams, Josephine C. Donovan (ed.), Animals \& Women. Feminist Theoretical Explorations, Duke University Press, Durham and London, 1995, p. 333.

49 J. Martínez Alier, El ecologismo de los pobres. Conflictos ambientales y lenguajes de valoración, Icaria, Barcelona, 2004.

50 Cf. A. Puleo, «De Marcuse a la sociobiología. La deriva de un feminismo no ilustrado», en Isegoría. Revista de Filosofía Moral y Política, n. ${ }^{\circ}$ 6, CSIC, Instituto de Filosofía, Madrid, noviembre 1992, pp. 113-128. 
Por otro lado, la especie humana no puede seguir multiplicándose sin invadir y saquear los escasos territorios salvajes que restan. Sheri Tepper, en esa fábula de tintes ecologistas que es Beauty ${ }^{51}$, asocia la política involutiva de la derecha norteamericana con respecto a los derechos sexuales y reproductivos de las mujeres con la «apropiación humana de la producción primaria neta de biomasa (HANNPP)». La heroína de esta distopía termina por descubrir que la extraña ciudad del futuro llamada Feedepoor a la que se canalizan todos los alimentos en un mundo devastado por la técnica y cubierto de hormigón, debe su nombre a la aparentemente bienintencionada consigna feed the poor que, en realidad, perseguía la extensión sin límites de la producción y el consumo ${ }^{52}$. Curiosamente, una simple novela de ciencia ficción popular se atreve a mencionar un tema que, a menudo, parece tabú para el ecofeminismo.

\section{Aceptar con prudencia los beneficios de la ciencia y la técnica}

Los ídolos modernos por antonomasia son la ciencia y la tecnología. La «tecnolatría» es una actitud cada vez más extendida. Es indudable que las comodidades de que gozamos son posibles en gran medida gracias al desarrollo tecnológico y que esta convicción alimenta la confianza ilimitada en el poder de la invención técnica. Las diversas teorías ecofeministas han marcado una fuerte distancia crítica con respecto a los fundamentos, objetivos y prácticas del complejo tecno-científico. Llevando al centro de la atención hechos generalmente escamoteados a la opinión pública como los fenómenos de iatrogenia o los perniciosos efectos medioambientales de la civilización del petróleo, sus teóricas han equilibrado con oportunas pinceladas de sombra un cuadro demasiado radiante para ser real.

Sin embargo, el efecto final de la lectura de algunos de sus textos parece plantear a menudo el dilema de optar entre una vida pre-industrial natural y solidaria o abandonarse a la vorágine egoísta, destructora y culpable de la sociedad de consumo de Occidente. Como muy poca gente que se halle en esta última va a elegir la primera, y quizás ni siquiera los habitantes de las comunidades agrícolas del Sur deseen en masa renunciar a los beneficios de la modernización, la crítica se desactiva a pesar de su radicalidad, o justamente a causa de ella.

51 Para un estudio de las transposiciones literarias de las ideas ecológicas de Tepper, ver Lucile Desblache, «Las pasiones ecológicas de Sheri Tepper», en Carmen Velayos, Olga Barrios, Ángela Figueruelo y Teresa López de la Vieja (eds.), Feminismo ecológico, Estudios multidisciplinares de género, ed. Universidad de Salamanca, 2007, pp. 53-70.

52 Observemos que, actualmente, las multinacionales de los transgénicos buscan convencer a la opinión pública de que han encontrado «la solución» al hambre en el mundo y presentan a los ecologistas como un obstáculo para aplicarla. 
El ecofeminismo ilustrado no será ni tecnofóbico ni tecnólatra. Exigirá el cumplimiento del principio de precaución asumido en tratados internacionales y en los documentos de la Unión Europea en materia de ciencia y tecnología ${ }^{53}$. La carga de la prueba corresponde a quien plantea una nueva actividad o producto, no a los potenciales afectados. Como ha puesto de relieve Jorge Riechmann ${ }^{54}$, la aplicación de este principio se enfrenta a la vertiginosa aceleración del tiempo mercantilizado en el que el cuerpo humano y el medio ambiente se convierten en laboratorios donde tienen lugar experimentos de alto riesgo.

Para el ecofeminismo ilustrado, el problema de las modificaciones tecnocientíficas de la naturaleza no residirá en la alteración de un orden sagrado, sino en lo rudimentario y tosco de la intervención humana actual sobre adaptaciones sistémicas complejas con un pasado de millones de años. Los «daños colaterales» y la posible irreversibilidad de los cambios hacen que debamos examinar las innovaciones a la luz de los Derechos Humanos (particularmente el derecho a la salud en un medio ambiente sano), y teniendo en cuenta la herencia que dejamos a las generaciones futuras. Una de las razones por las que la ecología se convierte en una cuestión feminista es el hecho de que, por causas biológicas ${ }^{55}$, la contaminación tiene particular incidencia en la salud de las mujeres.

Entre los beneficios actuales de la ciencia y la técnica debe destacarse el campo abierto por las tecnologías de la información y la comunicación (TIC). El feminismo tiene una larga trayectoria de adhesión a la esperanza moderna en la ciencia y en los últimos años ha reflexionado sobre la necesidad de impulsar su presencia en ese nuevo espacio abierto por Internet ${ }^{56}$, Red de Re-

53 Este principio está lejos de ser cumplido, como lo prueba la resistencia, recortes y postergación a la puesta en práctica de la iniciativa REACH en la Unión Europea.

54 Jorge Riechmann, Un mundo vulnerable. Ensayos sobre ecología, ética y tecnociencia, ed. Los libros de la Catarata, Madrid, 2005, pp. 283-310. Del mismo autor, Tiempo para la vida. La crisis ecológica en su dimensión temporal, ed. del Genal, Málaga, 2003.

55 Puesto que las sustancias químicas tóxicas se fijan en la grasa y el cuerpo femenino tiene una mayor proporción de tejido graso y más inestabilidad hormonal, la contaminación afecta más a las mujeres. Esto explica que presenten más frecuentemente que los hombres el síndrome de hipersensibilidad química múltiple (SHQM) y otras patologías resultantes del deterioro ambiental (The Boston Women's Health Book Collective, 2000, pp. 477-478). Distintas organizaciones, entre ellas la Red Medioambiental de Mujeres, han señalado que el alarmante aumento del cáncer de mama de los últimos cincuenta años está causado principalmente por la exposición a xenoestrógenos, término que designa a las sustancias químicamente similares a las hormonas femeninas (pesticidas organoclorados, dioxinas de las incineradoras, resinas sintéticas, y otras sustancias contenidas en productos de limpieza, envoltorios de plástico, pinturas, etc.). La exposición puede ser directa (por ejemplo, en zonas cercanas a cultivos fumigados) o a través de la ingestión de alimentos contaminados (observándose gran concentración de estos productos en las grasas animales).

56 Sobre el ciberfeminismo social y activismo feminista, ver Boix, Montserrat, Hackeando el patriarcado en la lucha contra la violencia hacia las mujeres. Filosofia y práctica de mujeres en red desde el ciberfeminismo social, en Labrys (www.unb.br/ ih//his/gefem). También 
des, en lo que puede definirse como voluntad de participación democrática. Las cibercampañas ecofeministas sobre salud y desarrollo sostenible son ejemplos paradigmáticos de las nuevas formas de acción ciudadana ${ }^{57}$.

La autonomía de las mujeres se ha visto incrementada con la civilización tecnológica de diversas maneras. No desearíamos volver a estadios precedentes. Sin embargo, este reconocimiento no nos exige una aceptación ciega. Podemos y debemos criticar sus excesos destructores y la instrumentalización que siempre nos amenaza. Los griegos conocían los peligros de la soberbia humana que no reconoce límites. La llamaron hybris.

\section{Fomentar la universalización de los valores del cuidado hacia los humanos y la Naturaleza}

Podemos considerar las identidades de género que, estadísticamente, caracterizan a los humanos de uno y otro sexo como un resultado del sistema estratificado de género en el que nos socializamos. Incluso si se prueba sin lugar a dudas la existencia de diferencias biológicas con claros efectos causales en actitudes y comportamientos atribuidos a los sexos, seguiría siendo cierto que la cultura y las relaciones sociales tienen un peso determinante en su modelado, represión o fomento. De las virtudes, asociadas a las identidades, puede decirse que, estadísticamente, tienen género.

Ciñéndose al ámbito de las relaciones entre humanos, Victoria Camps ha defendido una visión positiva de las virtudes del cuidado, tradicionalmente desarrolladas por las mujeres en la familia, y ha afirmado la necesidad de su universalización: «si el cuidar es un valor ético primordial, será una obligación de todos, no sólo de las mujeres» ${ }^{58}$. La ética del cuidado y la ética de la justicia han de complementarse ${ }^{59}$. Al otorgar rango moral a los sentimientos, se enriquece el pensamiento ético y se establecen bases sólidas para las virtudes públicas.

Del nominalismo moderado se puede derivar la demanda de una universalización de las virtudes del cuidado, históricamente femeninas. Las mujeres

puede consultarse Ana de Miguel y Montserrat Boix, Los géneros en la red: los ciberfeminismos (http://www.nodo50.org/mujeresred/cyberfeminismo.html) y Remedios Zafra, Habitar en (punto) net, Servicio de Publicaciones de la Universidad de Córdoba, 2004.

57 Se trata, manifiestamente, de acción ciudadana en los tres entornos definidos por Javier Echeverría: E1 Naturaleza/cuerpo, E2 Ciudad/Sociedad y E3 Telecomunicaciones/Red (Javier Echeverría, Los Señores del Aire. Telépolis y el Tercer Entorno, Destino, Barcelona, 1999). Sobre la necesidad de que los usuarios se transformen en «e-ciudadanos», ver Javier Echeverría, «Tecnociencias de la información y participación ciudadana», en Isegoría. Revista de Filosofía Moral y Política, n. ${ }^{\circ}$ 28, CSIC, Instituto de Filosofía, Madrid, julio 2003, pp. 73-92.

58 Victoria Camps, La voluntad de vivir, Ariel, Barcelona, 2005.

59 Victoria Camps, El siglo de las mujeres, Cátedra, Madrid, 1998. Ver también V. Camps, Virtudes públicas, Espasa, Madrid, 1990. 
hemos incorporado masivamente a lo largo del último siglo ciertas características funcionales en el ámbito de lo público y calificadas de «masculinas». El fenómeno inverso se ha producido en un grado infinitamente menor.

En tanto las conductas y habilidades de los hombres se presentan simplemente como neutras, como atributos eminentemente humanos, su adopción toma la forma de conquista de un status que nos ha sido injustamente negado. La devaluación de las actitudes y habilidades asociadas a las mujeres, vividas y concebidas como lo particular, contingente y finito frente a lo universal, necesario y eterno bloquea la salida de una situación de desigualdad en roles asimétricos.

En las huellas del primer ecofeminismo, pero con una fuerte toma de posición multicultural, el ecofeminismo deconstructivo ha creído detectar en las mujeres y en otros grupos no dominantes, como los pueblos indígenas, un sentido del self interconectado con otras formas de vida y más vinculado a una ética del cuidado que a una ética de los derechos entre individuos, propia de la patriarcal Modernidad. Se trataría de una noción colectiva de concern (solicitud) que no estaría basada en la competición y el conflicto ${ }^{60}$. Pero de ahí han deducido que la primera debía reemplazar a los derechos, calificados de masculinos y que era suficiente para resolver el problema de los abusos humanos sobre la Naturaleza.

Lo que Celia Amorós ha llamado «articulación étnica del reconocimiento» ${ }^{61}$, o momento de la crítica al androcentrismo en el que se exige el reconocimiento del valor de ciertos rasgos del genérico femenino, puede constituir un buen comienzo si no se limita a la autocomplacencia y no deriva en una ontologización diferencialista. La valorización de la empatía y el cuidado frente a enfoques puramente cognitivos y procedimentales de la razón práctica manifiesta un paso hacia la superación del dualismo razón-emoción y un elemento importante en la crítica a la constitución de la identidad viril patriarcal como separación y negación de los valores del cuidado representados por la figura femenina materna. Pero este reconocimiento de «otra voz» de la ética no deberá llegar al eliminacionismo. El rechazo del concepto de derechos por su supuesto sesgo androcéntrico equivale a confundir las abstracciones con su perfil de género.

El análisis del «sujeto iniciático» ${ }^{62}$ facilita la comprensión de aquellos aspectos de las identidades patriarcales que es necesario cuestionar para acercarnos a la igualdad entre los sexos y a una nueva forma de relación con la Naturaleza. Por supuesto, esta crítica no pretenderá reemplazar la denuncia

60 Sobre la relación del yo ecológico con los trabajos de las psicoanalistas feministas, ver María Luisa Cavana, «La relación instrumentalizadora con la Naturaleza», en María Luisa Cavana, Alicia Puleo y Cristina Segura, op. cit., pp. 11-20.

${ }^{61}$ Celia Amorós, La gran diferencia..., ed. cit., p. 372.

62 La expresión es de Celia Amorós y su tratamiento puede consultarse en su obra Tiempo de feminismo. Sobre feminismo, proyecto ilustrado y postmodernidad, ed. cit., pp. 21-22. 
de los intereses económicos implicados en la devastación medioambiental. Pero tampoco puede obviarse si queremos una transformación ético-política profunda que vaya más allá de una mera gestión racional de los recursos. Coincido con Celia Amorós en considerar que, para universalizar la ética del cuidado, ésta ha de predicarse fundamentalmente a los varones puesto que de otra manera reforzaría los inmemoriales hábitos de sacrificio femeninos ${ }^{63}$. Cabe agregar, además, que es indudable que la adopción de las virtudes del cuidado por parte del genérico masculino les otorgará el prestigio de su estatus.

$\mathrm{Al}$ respecto, resulta interesante observar que el feminismo y el ecologismo coinciden en develar que el mundo de lo público, concebido tradicionalmente como esfera de la libertad, se alimenta (literal y metafóricamente) del ámbito doméstico de la necesidad. En este ámbito de lo cotidiano se dan virtudes y obligaciones morales relacionadas con la sostenibilidad. Destaca Andrew Dobson que la ciudadanía ecológica coincide con la propia del republicanismo clásico en la idea de bien común pero difiere en la importancia concedida al ámbito privado ${ }^{64}$. Pero en lo que no deja de ser un rasgo de androcentrismo, Dobson procede a una jerarquización de las virtudes de la ciudadanía ecológica que propone. Simpatía, cuidado y compasión son consideradas «virtudes secundarias» que permiten el ejercicio efectivo de la justicia, virtud fundamental. Desde una perspectiva muy diferente, la ecofeminista Karen Warren piensa la ética ecológica como «un cambio en la actitud desde la percepción arrogante hacia la percepción afectiva del mundo no humano» ${ }^{65}$.

Universalizar la ética del cuidado postgenérica y ecológica es una asignatura pendiente de la educación ambiental. Cuando lo hayamos logrado, no sólo habremos conseguido un reparto equitativo de las tareas cotidianas indispensables para la vida humana y mejorado la calidad de esta última en general ${ }^{66}$, sino que habremos reconocido, por fin, las estrechas relaciones internas del proceso de los sentimientos, el intelecto y la racionalidad práctica y habitaremos de forma más pacífica la Tierra.

\section{Asumir el diálogo intercultural}

Ya me he referido a la tendencia, presente en algunas formas de ecofeminismo, a suspender el juicio crítico cuando se trata de culturas no occidentales. Mientras que los principios y prácticas del liberalismo aparecen como la causa de todos los males, se mira con benevolencia y respeto hacia culturas que

63 C. Amorós, La gran diferencia..., ed. cit., p. 205.

64 Andrew Dobson, «Ciudadanía ecológica», Isegoría. Revista de Filosofia Moral y Politica, n. ${ }^{\circ}$ 32, CSIC, Instituto de Filosofía, Madrid, junio 2005, pp. 47-62.

${ }^{65} \mathrm{~K}$. Warren, «El poder y la promesa de un feminismo ecológico», en María Xosé Agra (ed.), Ecología y Feminismo, ed. cit., p. 134. 
no siempre son el mejor de los mundos posibles. Si el ecofeminismo esencialista tiende a idealizar un «nosotras» hipostasiado y cuasi-biológico que estaría más cerca de la Naturaleza que la virilidad, las tendencias deconstructivas recientes asignan una importancia fundamental a las categorías de clase y etnia haciendo visibles las diferencias entre las mujeres y señalando las conexiones entre las diferentes dominaciones. Pero, en esta tarea, la impronta del multiculturalismo también conduce, en ciertos casos, a una visión acrítica.

En el Ecological Feminism deconstructivo, las influencias del pensamiento postmoderno, del comunitarismo, de los llamados «feminismos de color» ${ }^{67} \mathrm{y}$ del holismo ecológico ${ }^{68}$ se hacen sentir en el rechazo de los principios universales y la adopción de una ética contextual dependiente de los relatos interpretativos que configuran el mundo. El multiculturalismo y la Deep Ecology de que se nutre esta corriente deconstructiva tienen en común el punto de partida holista para el cual la comunidad o el ecosistema poseen un valor infinitamente superior al individuo. De ahí la fascinación por pueblos indígenas con culturas sostenibles que no han participado en el proceso de desarrollo de la Modernidad la cual, como sabemos, tiene el rostro jánico de los derechos individuales y de la destrucción medioambiental. Un ejemplo de esta fascinación y de la rendición al paradigma holista es la exaltación de la caza relacional de los sioux en la obra de Karen Warren ${ }^{69}$. En una hipertrofia emic, esta pensadora afirma que el ciervo «acepta» la necesidad de la relación establecida en el ritual de agradecimiento y da su vida para la supervivencia de quien lo ha matado. El auge del multiculturalismo y la atracción que ejerce sobre numerosas pensadoras feministas su denuncia de la globalización homogeneizadora e imperialista no nos deben hacer olvidar su relativismo cultural, que funciona como interruptor de cualquier crítica a la dominación interna. Los oprimidos pueden, y a menudo son, a su vez, opresores, aunque lo específico no encierre siempre dominación. De ahí la conocida advertencia de Nancy Fraser ${ }^{70}$ para que evitemos tanto una versión indiscrimi-

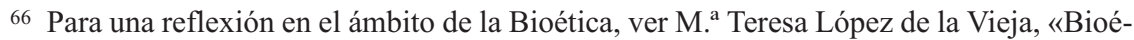
tica. Del cuidado al género», en M. T. López de la Vieja, O. Barrios, A. Figueruelo, C. Velayos y J. Carbajo (eds.), Bioética y feminismo. Estudios multidisciplinares de género, Ed. Universidad de Salamanca, 2006, pp. 107-127.

67 Con respecto a éstos, observa Rosa Cobo que, al prescindir de la categoría de patriarcado como contrato sexual transcultural, pierden una herramienta fundamental para el proyecto político feminista (Rosa Cobo, «Ellas y nosotras en el diálogo intercultural», en Rosa Cobo (ed.), Interculturalidad, feminismo y educación, Epílogo de Celia Amorós, Secretaría General Técnica del Ministerio de Educación y Ciencia y Ediciones de la Catarata, 2006, pp. 11-33).

68 Aldo Leopold, Una ética de la tierra, ed. de Jorge Riechmann, trad. Isabel Lucio-Villegas Uría y Jorge Riechmann, Los libros de la Catarata, Madrid, 2000.

69 Karen Warren, «The power and the Promise of Ecological Feminism», en K. Warren, (ed.), Ecological Feminist Philosophies, Indiana University Press, Hypatia Book, Bloomington \& Indianapolis, 1999, pp. 35-36.

70 Cf. Iustitia Interrupta, trad. M. Holguín, I. C. Jaramillo, Universidad de los Andes, Bogotá, 1997. 
nada del pluralismo como un rechazo a toda identidad diferencial concebida como ficción represiva.

Mientras que el multiculturalismo extremo ve las culturas como totalidades inconmensurables entre sí, el diálogo intercultural, tal como ha sido tematizado en el feminismo por Celia Amorós ${ }^{71}$, concibe las distintas realidades culturales como procesos dinámicos que se enriquecen con la mutua interpelación capaz de producir fenómenos de reflexividad indispensables para la construcción de la igualdad entre los sexos. En referencia polémica a Lévi-Strauss, esta filósofa nos recuerda que «hay que discutir todas las reglas de todas las tribus» ${ }^{72}$. Aplicando esta afirmación al proyecto de un ecofeminismo ilustrado, trataremos de aprender de culturas sostenibles como oportuno correctivo a nuestra civilización suicida pero no caeremos en una admiración beata de lo ajeno e incapaz de reconocer en lo propio algo que ofrecer a los demás.

La ecología nos ha enseñado el valor de la biodiversidad. Ahora sabemos que los ecosistemas son complejos relacionales en los que todos los elementos cumplen una función y son producto de adaptaciones inmemoriales. Pero este reconocimiento no es automáticamente traducible a las sociedades humanas y a sus prácticas a través de un holismo ético que compromete la herencia liberal de reconocimiento de la individualidad con lo que ello podría tener, incluso, de beneficioso para los no humanos. Los criterios que han de dirigir el diálogo intercultural del ecofeminismo ilustrado serán la sostenibilidad, el nivel de violencia ejercida y los Derechos Humanos, con especial atención a los de las mujeres por ser los más ignorados transculturalmente.

\section{Afirmar la unidad y continuidad de la Naturaleza}

En una época en la que el neocreacionismo ${ }^{73}$ intenta deslegitimar las evidencias científicas con el objetivo de devolver al ser humano a lo que Kant llamó «culpable minoría de edad», aumentar la desigualdad entre hombres y mujeres, restaurar el abismo ontológico entre humanos y no humanos e impedir

71 Amorós, «Feminismo y multiculturalismo», vol. 3.

72 Amorós, vol. 3, p. 234.

73 Los evangelistas neocreacionistas y los partidarios de la Teoría del Designio Divino rechazan la división entre ciencia y religión y niegan la existencia del cambio climático. Se oponen a la teoría de la evolución de Darwin, lo que ha dado lugar a diversos conflictos en centros educativos. Sostienen que las verdades han de ser buscadas en la lectura literal de la Biblia. Se están implantando en Europa a través del Discovery Institut, fundación estadounidense destinada a la difusión y captación de adeptos. Ejercen gran atracción entre numerosos jóvenes en busca de normas y certidumbres absolutas. Preconizan el retorno a una moral sexual y a unos roles de género extremadamente rígidos y tradicionales en los que el lugar natural de las mujeres es el hogar y su función exclusiva, además del proselitismo neocreacionista, es el ser esposas y madres. 
que se adopten medidas imprescindibles para detener o paliar la devastación ambiental, el ecofeminismo ilustrado afirmará, en el camino abierto por Darwin y Margulis ${ }^{74}$, la unidad y continuidad de la Naturaleza y señalará la necesidad de una reconceptualización de lo humano que se haga cargo de la responsabilidad moral ${ }^{75}$ que conlleva el nuevo poder tecnológico de la especie. Huérfanos de guías providenciales y despojados de coartadas teleológicas, descubrimos nuestra insignificancia en la infinitud del cosmos. En el universo desencantado por la ciencia, la técnica y la filosofía, sólo una mirada empática hacia humanos y no humanos puede rescatarnos del nihilismo. No somos los únicos seres arrojados a la cruel vorágine del devenir. Poseemos el privilegio de conceptualizarlo pero no la exclusividad de vivirlo. Ya en el materialismo del siglo de las Luces surge la reflexión sobre la consideración moral hacia todos los seres vivos capaces de sufrir. Esta evolución de la ética no sólo no es incompatible con el espíritu ilustrado, sino que pertenece a su misma historia, bien es verdad que, como fuera el caso del feminismo, en tanto corriente minoritaria e ignorada. No es una casualidad si las actitudes de compasión ante la vulnerabilidad de los animales han sido tradicionalmente devaluadas como debilidad femenina.

El ecofeminismo ilustrado se apoyará en una ética antropocéntrica moderada (débil) que no desprecie la actitud empática y los sentimientos de piedad. No será ecocéntrico, aunque reconozca que el carácter atomista del antropocentrismo débil - declarado insuficiente para un enfoque ecológico por diversas ecofeministas y pensadores de la Deep Ecology ${ }^{76}$ - debe ser completado con una comprensión holista de los sistemas naturales, proporcionada por los conocimientos científicos actuales de la ecología, y destinada a favorecer las buenas prácticas. Considero que la complejidad, propuesta como piedra de toque por algunas éticas ecocéntricas, más que un criterio propiamente moral puede ser un indicador del grado de riesgo de desequilibrio del sistema del que dependen todos los seres vivos.

74 Sorprende la similitud de la concepción de Diderot sobre el cuerpo, colonia de células que se van reemplazando como los monjes de un convento, con la teoría de Lynn Margulis de los organismos como comunidades de células auto-organizadas y con potencial evolutivo. El materialismo energetista del autor de Le Rêve de D'Alembert plantea también la hipótesis de los híbridos interespecies (que, por supuesto, no son todavía las bacterias de la simbiogénesis de Margulis).

75 La idea de responsabilidad ecológica puede ser de procedencia ilustrada o de raigambre teológica. Así lo señala Javier Muguerza al analizar el concepto de de responsabilidad de Hans Jonas como perteneciente al segundo tipo (J. Muguerza, «¿Convicciones y/o responsabilidades? (Tres perspectivas de la ética en el siglo XXI)», en Revista Laguna, n. ${ }^{0} 11$, septiembre 2002, pp. 23-45.

76 J. Baird Callicott, «Introduction», en Michael Zimmerman, Baird Callicott, Karen Warren, Irene Klaver y John Clark, Environmental Philosophy. From Animal Rights to Radical Ecology, Pearson, Fourth edition, New York, 2005, pp. 5-15. 
Ética, Política y hasta Estética ${ }^{77}$ se hallan comprometidas en esta convicción de la unidad de la Naturaleza a través de los conceptos de benevolencia y belleza.

\section{Una nota final sobre la sostenibilidad}

Como reflexión feminista sobre las relaciones humanas con la Naturaleza, el ecofeminismo ilustrado implica una revisión que corrige, gracias a la articulación teórica de la experiencia histórica emancipatoria de las mujeres, los sesgos del antropocentrismo extremo y del androcentrismo pseudouniversalista del discurso ilustrado.

Libertad, igualdad, fraternidad fue el lema de la revolución que abrió paso a las modernas democracias europeas. El tercer elemento de esta tríada, proveniente del lenguaje religioso y del sentimiento de pertenencia de los gremios del Antiguo Régimen, no ha recibido un tratamiento tan extenso por parte de la Filosofía Política como los dos primeros. Se ha considerado incluso que, en tanto sentimiento, no tenía lugar junto a los dos principios que le preceden. Por otro lado, se ha subrayado, con razón, que su misma raíz etimológica revela connotaciones patriarcales que la pintura neoclásica de David expresa claramente en El Juramento de los Horacios ${ }^{78}$.

La fraternidad ha sido relacionada con el sentimiento moral que predispone a una distribución social más justa de los recursos y del reconocimiento, e interpretada como principio normativo fundamental en la teoría rawlsiana. En esta época del cambio climático, la desertización y la desaparición de la biodiversidad, la fraternidad ha de incluir no sólo la justicia redistributiva y la justicia en el reconocimiento, sino también la sostenibilidad. Sostenibilidad es fraternidad con el conjunto de la ciudadanía, con la cual nos comprometemos a preservar el espacio de vida común, y es responsabilidad con las generaciones futuras. Es fraternidad con los más vulnerables a la contaminación y a la degradación de la Tierra: mujeres, niñas y niños, personas pobres del Sur. $\mathrm{Y}$, en el convencimiento de que «no hay camino sino estelas en la mar», para nuestra mirada postmetafísica que ha descubierto la radical finitud de un universo indiferente en el que sólo nuestras huellas trazan las sendas, sostenibilidad es también compasión por ese Otro silencioso e ignorado, pero capaz de sentir, desear, anhelar, amar y, por todo ello, sufrir.

77 Marta Tafalla, «Por una estética de la naturaleza: la belleza natural como argumento ecologista», en Isegoría. Revista de Filosofía Moral y Política, n. ${ }^{\circ} 32$, CSIC, Instituto de Filosofía, Madrid, junio 2005, pp. 215-226. Ver también Ana Patricia Noguera, El reencantamiento del mundo, Programa de las Naciones Unidas para el Medio Ambiente. PNUMA-Oficina Regional para América Latina y el Caribe, Universidad Nacional de Colombia, 2004.

78 Celia Amorós, La gran diferencia..., ed. cit. 